\title{
Do visitors gaze and reproduce what destination managers wish to commercialise? Perceived and projected image in the UNESCO World Heritage area 'West Norwegian Fjords'
}

\author{
Iratxe Landa Mata* \\ Institute of Transport Economics, \\ Oslo, Norway \\ Email: ilm@toi.no \\ *Corresponding author

\section{Knut Fossgard} \\ University of Life Sciences in Norway, \\ Universitetstunet 3, 1430 Ås, Norway \\ Email: knut.fossgard@nmbu.no
}

\author{
Jan Vidar Haukeland \\ Institute of Transport Economics, \\ Oslo, Norway \\ Email: JanVidar.Haukeland@toi.no
}

\begin{abstract}
Destination image plays a key role in helping people decide where to travel and affects satisfaction, likelihood of return visits and word of mouth. While photography is not the only way of projecting and perceiving an image, ' $a$ picture paints a thousand words'. The rise of social media and usergenerated content has made the image formation process more complex, and has reduced the extent of control that tourism suppliers can exert on the image they wish to project. It is thus necessary to further investigate whether tourists reproduce the commercialised image in what the literature calls the 'hermeneutic circle of representation' or capture and share their own impressions. This study constructs a categorisation scheme for conducting photography-based image analysis to compare images of two Norwegian destinations as projected by destination management organisations with those shared by Instagram users (perceived image). Results indicate that this circle of representation is not hermeneutic.
\end{abstract}

Keywords: destination image; perceived-image; projected-image; circle of representation; user-generated-content; UGC; social media; Instagram; Nærøyfjord; Geirangerfjord.

Reference to this paper should be made as follows: Landa Mata, I., Fossgard, K. and Haukeland, J.V. (2018) 'Do visitors gaze and reproduce what destination managers wish to commercialise? Perceived and projected image in the UNESCO World Heritage area 'West Norwegian Fjords", Int. J. Digital Culture and Electronic Tourism, Vol. 2, No. 4, pp.294-321. 
Biographical notes: Iratxe Landa Mata is a researcher at the Institute of Transport Economics. Her research experience includes assessments of usergenerated content to explore their utility from a research and practical perspective. She is also concerned with understanding how public and private organisations can contribute to the sustainability of tourism, mobility and society at large. Her main research interests are sustainable tourism and travel behaviour.

Knut Fossgard is a PhD student and Lecturer in nature-based tourism at the Faculty of Environmental Sciences and Natural Resource Management at the University of Life Sciences in Norway. His research interests focus on the use of ICT in the nature-based tourism industry, with specific emphasise on tourism experience providers and the utilisation of natural resources in the delivery of nature-based tourism experiences.

Jan Vidar Haukeland holds a part-time position as Associate Professor at the Department for Ecology and Natural Resource Management, Norwegian University of Life Sciences and is a senior researcher at the Institute of Transport Economics. His professional experience includes teaching and supervision in nature-based tourism on master level. His research activities comprise a wide range of issues within the field of tourism: Nature-based tourism, management of tourism in protected natural areas, tourism impacts on local communities, national holiday surveys, foreign visitor surveys, tourists' expenditure surveys, welfare aspects of travel and tourism, alternative tourism, trend analyses of tourism developments, tourism marketing issues and tourism attraction studies.

\section{Introduction}

Tourism is based upon produced and consumed images (Latorre-Martínez et al., 2014). Destination image plays a key role in decisions about where to travel ( $\mathrm{Li}$ and Wang, 2011; Choi et al., 2007; Beerli and Martin, 2004; Baloglu and McCleary, 1999) and how destinations are experienced, which in turn affects satisfaction, re-purchase intention and word-of-mouth (WOM) (O'Leary and Deegan, 2005; MacInnis and Price, 1987). According to Crompton (1979), destination management organisations (DMO) can create their image only to the extent they manage to control the informational sources that contribute to the construction of that image. However, the rise of the internet, and especially of social media, facilitates the co-existence of multiple representations of destination image and makes the image formation process more complex (Choi et al., 2007).

This is so because social media builds on web 2.0, a term coined in 2004 (Kaplan and Haenlein, 2010), which differs from web 1.0 in that it facilitates a more dynamic exchange of information from many to many (Aalen, 2012) and allows users to shape content (Beckendorff et al., 2014). Web 2.0 enables individuals to be active producers of information, and increases the scope and breadth of user-generated content (UGC) on the web (Llodrà-Riera et al., 2015; Kang and Schuett, 2013; Munar and Steen Jacobsen, 2013; Lo et al., 2011; Xiang and Gretzel, 2010). 
The immediate consequence is that UGC complements the information that has traditionally been retrieved from online and offline supply-side material, family, friends and acquaintances, and mass media. Moreover, "word-of-mouth" (WOM) acquires greater significance online. This is because, despite a weaker relation between communicators and recipients, electronic-WOM (e-WOM) occurs at a larger scale, there is increased anonymity, and longer duration and high variability regarding the forms in which it may appear (Beckendorff et al., 2014; Camprubí et al., 2013). For instance, photographs are an important element in e-WOM, in contrast to WOM, which is predominantly verbal.

While photographs are not the only form of projecting and perceiving an image, they manage to communicate a lot of information at once. Photography and travel are intrinsically related (Kádár, 2014; Lo et al., 2011), and the image projected of a destination is traditionally produced through photography (Steen Jacobsen, 2007). Photographs often trigger the desire to visit a specific place (Urry, 1990) and travel photography serves to witness travel experiences, possess them, construct travel memories, and tell stories (Lo et al., 2011). With cameras as integral elements of smartphones, travellers can generate and share information on their travel experiences (Kavoura and Stavrianea, 2015; Munar and Jacobsen, 2013) in real time, and they can also use their phones to seek such information (Gretzel and Yoo, 2008). Thus, tourists not only consume but also produce places through photography (Larsen, 2006) and contribute to the "collective image of a destination" (Latorre-Martínez et al., 2014; Lo et al., 2011). This expands the range of informational material against which the tourism supply industry must compete (Lo et al., 2011) and reduces the level of control that tourism service providers, such as DMOs, can exert on the type of information available online (Scott et al., 2017; Miguéns et al., 2008).

Yet, is this control necessary at all? Studies carried out both before and after the arrival of Web 2.0, indicate that tourism photography takes places in a "hermeneutic circle of representation" (Stepchenkova and Zhan, 2013; Jenkins, 2003; Urry, 1990). If user-generated photographs in social media are generated by travellers seeking to mimic the commercial pictures projected by DMOs, then destination image may not remain as much outside their control. However, if social media users perceive, capture and share different pictures than those projected by DMOs, the implications may be considerable. This crucial difference and diverging results from empiric studies on this topic reviewed in next section justify the objective of this paper, which is to investigate whether travel photography takes place in a "hermeneutic circle of representation" (Stepchenkova and Zhan, 2013; Jenkins, 2003) on the web. More specifically, the study analyses and compares online photographs published by DMOs of two major Norwegian destinations - "Geirangerfjord" and "Ncerøyfjord" ("projected image") - with online photographs of those destinations shared by Instagram users ("perceived image").

This paper builds on previous studies analysing photography both offline (Santillán, 2010; Hunter, 2008; Larsen, 2006; Groves and Timothy, 2001; Markwell, 1997) and online (Stepchenkova and Zhan, 2013; Syed-Ahmad, 2011). It also employs results from an online survey of social media conducted among travellers that visited the "Geirangerfjord" and/or the "Ncerøyfjord" during the summer of 2015 to identify main "hashtags" used by travellers visiting these destinations when sharing their travel experiences (Dybedal, 2017). 


\section{Literature review}

\subsection{Destination image and the circle of representation}

Crompton (1979, p.18) defines destination image as the "sum of beliefs, ideas, and impressions that a person has of a destination". The process of constructing a destination image involves both cognitive and affective elements (Li and Wang, 2011). As such it is the result of being exposed to different informational stimuli. In addition to informational sources (including their variety, amount and type), personal factors such as motivation, socio-demographics (Baloglu and McCleary, 1999) and travel experience (Beerli and Martin, 2004) also affect the formation of destination image. Based on this and on the review conducted by Li and Wang (2011) on Crompton's and subsequent definitions, destination image can be defined as a constructed idea of a destination based on information processed over time from different sources, and affected by personal factors.

Informational sources can be broadly classified into primary and secondary (Beerli and Martin, 2004), or, respectively, internal and external (Li and Wang, 2011). Primary/internal sources are encountered or generated during the actual visitation (Li and Wang, 2011). Secondary/external sources can be classified as induced (e.g. DMO brochures), organic (e.g. information from friends and relatives) and autonomous (e.g. guidebooks) (Beerli and Martin, 2004). Based on this categorisation, O'Leary and Deegan (2005) speak of "organic" and "induced" images. Yet, the arrival of web 2.0 challenges traditional categorisations (Choi et al., 2007). Photographs that used to be shared among acquainted people in small, private groups, are now publicly shared in photo-based social media (Lo et al., 2011). Thus, web 2.0 augments the scale of "unsolicited" sources of information in the image formation process that are neither "induced" (they are provided by the tourists themselves) nor totally "organic" (users posting these photographs are not necessarily known by the receiver). A further categorisation used by researchers - as well as in this paper - is that of "perceived" and "projected" image. The former is a tourist-based image, while the latter is a marketerbased image ( $\mathrm{Li}$ and Wang, 2011).

Since Urry (1990) published "The Tourist Gaze", an academic discussion has been revolving around whether (or not) travel photography takes places in a "hermeneutic circle of representation" (Stepchenkova and Zhan, 2013; Månsson, 2011; Jenkins, 2003; Larsen, 2006). Urry (1990) argues that photographs contribute to the internalisation of ideal representations that tourists seek when visiting a particular destination, and that they, therefore, take pictures that reproduce the commercial images that they have previously consumed. Interestingly, studies investigating this topic come to different conclusions. As the discussion began before the uptake of social media, studies have analysed both online and offline photography.

Regarding offline photography, Jenkins (2003) found that pictures taken and/or preferred by backpackers travelling in Australia reproduced the country's stereotypes that were commercialised in tourism brochures distributed in Canada. On the contrary, Larsen (2006) compared "projected" and "perceived" images of Bornholm, revealing that commercial pictures differed from those taken by tourists with disposable cameras. As far as online photography goes, Stepchenkova and Zhan (2013) found both similarities and differences when comparing "projected" and "perceived" images of Peru. While both portrayed iconic archaeological sites framed in natural and mountainous landscapes, Flickr users were more interested in capturing daily life at the destination and less 
interested in "perfect" local traditions and festivals, which were more frequent in the official tourism website. Månsson (2011) - who did not limit the analysis to photography - investigated the post-travel social media practices of tourists who had visited the Rosslyn Chapel popularised in "The Da Vinci Code". The results led her to the idea that a shift was taking place: from a "circle of representation", in which the tourist is a passive consumer of media, to a "circuit of tourism", in which the tourist actively contributes to the creation of that media and the production of tourist spaces (ibid). Her conclusion is that the growth of internet, and especially of social media, has changed the tourist's role in the production of tourist spaces, thereby challenging the control that marketing players have traditionally exerted (Månsson, 2011). This matches with the notion that Bonini (2008) proposes to understand the process of learning in virtual environments (relation-centred approach), in which the users are not observers but interplay in/with the eco-system to continuously reshape knowledge.

Scott et al. (2017) reviewed studies investigating the implications of digital technology for DMOs. Their results suggest that DMOs are struggling to understand and account for the increasing effects of social technology on the consumer decision-making process. In their task of creating an image to promote their destination and make it more attractive, DMO messages are now blended with a much larger amount of information, not only from individual tourism suppliers located in the destination, who can now more easily reach out to the world, but also from visitors themselves. In an attempt to assist DMOs to make better choices Scott et al. (2017) proposed a new, less linear model, to describe the decision process of choosing a destination.

\subsection{Tourism photography analysis: state of the art}

Up until a couple of years ago, there were few studies focusing on analysing online UGC in the context of tourism (Latorre-Martínez et al., 2014; Leung et al., 2013) but such studies have proliferated in recent years. They have demonstrated the utility of UGC to study destination image (Chen et al., 2016; Garay Tamajón and Cánoves Valiente, 2015; Kladou and Mavgrani, 2015; Marine-Roig and Clavé, 2015; Li and Wang, 2011); conduct market analysis (Cheng and Edwards, 2015; Latorre-Martínez et al., 2014); identify tourism hot spots (Zhou et al., 2015); measure tourism activity (Kádár, 2014); and assess online participation and engagement (Alam and Diamah, 2012).

A few studies have also investigated user-generated photography in social media (Latorre-Martínez et al., 2014; Syed-Ahmad et al., 2009), and some have used geotagged photography to map tourism activity (Zhou et al., 2015; Kádár, 2014; LatorreMartínez et al., 2014). However, we are aware of few studies investigating destination image through the analysis of online user-generated photography. Stepchenkova and Zhan (2013) applied content analysis to identify Peru's most frequent attributes in both pictures broadcasted by the official tourism organisation on its website and usergenerated pictures posted in Flickr, and constructed "aggregated" maps of Peru's image by employing statistical analysis. Syed-Ahmad (2011) assessed user-generated photography to understand the representation of Islamic tourism in social media and responses to those images. Also, Månsson (2011) assesses destination marketing through, among other, photography. However, she focuses on analysing the tourists' role in creating image and their interaction with different social media and their users, instead of on dissecting photographs, which is what this study attempts. 
Fortunately, there are a number of studies that have analysed offline photography in tourism to investigate destination image, either from the demand side (Prestholdt and Nordbø, 2015; Groves and Timothy, 2001; Markwell, 1997), the supply side (Santillán, 2010; Hunter, 2008), or both (Larsen, 2006; Jenkins, 2003). One of these studies has analysed photographs of Norwegian destinations (Prestholdt and Nordbø, 2015). In this study, photographs taken by travellers equipped with disposable cameras were examined using visual content analysis to assess how tourists and locals evaluated summer landscapes of five Norwegian winter destinations ("Geilo", "Hovden", "Rauland", "Rjukan", and "Vrådal"). The results indicate that respondents generally appreciate destinations where natural, cultural and built-up landscapes form a unit. Yet, results also show differences among different groups of tourists. International tourists' photographs are largely based on natural landscapes, while Norwegians - and especially locals - are more aware of local building traditions and, especially, of the unattractive elements. Yet, Prestholdt and Nordbø (2015) use offline user-generated pictures and not user-generated pictures shared on social media.

Thus, due to the relatively low number of studies assessing online pictures (Stepchenkova and Zhan, 2013; Syed-Ahmad, 2011), studies focusing on offline pictures (Santillán, 2010; Hunter, 2008; Larsen, 2006; Markwell, 1997; Groves and Timothy, 2001) were also key for constructing an appropriate categorisation scheme to assist the analysis of online pictures generated by both the user and supply sides. Table A1 in the Appendix provides an overview of the studies used to construct the categorisation scheme presented in next section. It includes both offline and online studies, in which content analysis is a commonly employed methodology. This categorisation scheme assists the process of deciding whether images perceived by Instagram users reflect the images that DMOs seek to project, as well as it reveals important similarities and differences between the two destinations.

\section{Method and sample}

\subsection{The study area}

Both the "Ncerøyfjord" and the "Geirangerfjord" are iconic and well-visited destinations located in southwestern Norway, and are a main part of the UNESCO World Heritage area "West Norwegian Fjords". The main destination in the "Ncerøyfjord" area is the village of "Flåm", which in 2015 received 742,400 tourists, of which about 182,400 were cruise passengers (Dybedal, 2017). "Flåm" and the "Flåm" railway are important elements in a popular round trip called "Norway in a Nutshell". In the "Geirangerfjord" area, the main destination is the village of "Geiranger", which in 2015 was visited by 744,500 tourists, of which about 314,000 were cruise passengers (ibid). The "Geirangerfjord" is marketed by "Destination Ålesund and Sunnmøre" (www.visitalesund-geiranger.com), while the "Ncerøyfjord" is marketed by "Visit Sognefjord" (http://en.sognefjord.no/) and "Flåm AS" (www.visitflam.com).

\subsection{Selection of online photographs}

Given the rise and relevance of the digital media in destination promotion (Scott et al., 2017) and its implications for DMOs concerning destination choice, it was clear to us 
that the analysis needed to focus on online photography. This has also practical advantages, as the process of collecting and analysing data can be performed with relatively minor expense (Gennari, 2008). Yet, we were also aware of the contextual information (e.g. motivations) that analysis of offline photography could have provided, as its collection usually requires some kind of interaction between the photographer and the researcher (Larsen, 2006; Groves and Timothy, 2001; Markwell, 1997).

\subsection{1 "Perceived image"/Photographs posted by Instagram users}

Instagram is a popular social media that allows users to share pictures and videos online (thus, representative of web 2.0), either publicly or privately. It accounts for 600 million registered users (registration is free) and supports over 30 languages (Instagram, 2017). In contrast, DMO websites are more characteristic of web 1.0 internet.

The selection of photographs from Instagram followed criteria proposed by Stepchenkova and Zhan (2013), which combine randomisation with the number of comments/likes gained by a photograph, which gives some indication of their impact (Alam and Diamah, 2012). For each destination and hashtag, every $9^{\text {th }}$ photograph with at least twenty likes and one comment was selected. Where this criterion was not met, the next photograph was selected, i.e. the $10^{\text {th }}$, then the $8^{\text {th }}$, etc. This process took place without logging onto Instagram such that search results were not influenced by criteria linked to the researcher's profile such as contacts, previous search history or followed users. Up to 15 photographs were selected for each hashtag.

Results from an online survey conducted during the summer of 2015 were used to identify the most commonly used hashtags by travellers visiting the "Geirangerfjord" and "Ncerøyfjord" that summer, who had shared travel experiences on social media. For the "Geirangerfjord", most commonly used hashtags were \#geirangerfjord, \#geiranger, \#trollstigen, \#dalsnibba and \#hellesylt. For the "Norøyfjord", "hashtags" included \#flam, \#flåm, \#flaam, \#sognefjord, \#sognefjorden, \#flåmsbana and \#aurlandsfjord. Additionally, fifteen photographs posted under each \#visitgeiranger and \#visitflam were also selected. When identifiable, photographs posted by DMOs and local businesses were excluded from the analysis as it can be assumed that such firms would tend to express the destination's "projected image". This filter process showed that Instagram usage among businesses in the "Geirangerfjord" is lower than in the "Ncerøyfjord".

The initial number of Instagram photographs collected as the basis of analysis of the "perceived image" of the "Geirangerfjord" and the "Ncerøyfjord", were 90 and 120, respectively. This was then reduced to 85 and 90 photographs, respectively, due to the exclusion of photographs that were either duplicates, or depicted destinations other than those under investigation. The hashtag "\#flam" was excluded from the analysis of the "perceived image" of "Ncerøyfjord", as it displayed many pictures that were not related to the "Norøyfjord".

At this point, it should be mentioned that the downside of using Instagram, despite its popularity, is that one can only search for one hashtag at a time. Thus, it is not possible to combine words, as Stepchenkova and Zhan (2013) did in their analysis of photographs posted on Flickr, to distinguish pictures posted by travellers from those laid out by locals (e.g. by combining the search words "travel" and "Peru"). It is possible therefore that photographs used in the analysis were laid out by users other than travellers. Nevertheless, using "hashtags" that proved to be popular among travellers visiting 
the investigated destinations or that have a direct connection with their marketing (\#visitgeiranger and \#visitflam), reduces this uncertainty to some extent.

\subsection{2 "Projected image"/photos posted by DMOs}

Photographs posted on Instagram by DMOs from both destinations were identified by searching for the DMO usernames, @visitgeirangerfjord and @visitflam. However, since the number of photographs found was very low (five for @ visitgeirangerfjord and nine for @visitflam), it was necessary to complete the sample with further photographs selected from the official websites marketing the "Geirangerfjord" (www.visitalesundgeiranger.com) and the "Ncerøyfjord" (www.visitflam.com). Photographs were selected from the corresponding websites' photograph services, which can be assumed to represent the image that these destinations wish to project. In the case of the "Geirangerfjord", a filter had to be applied to search for photographs of the "Geirangerfjord" and not of other destinations within the "Sunnmøre" region (e.g. Ålesund), which are also marketed by this DMO.

Due to the lower number of photographs on these websites, every $5^{\text {th }}$ photograph was selected (instead of every $9^{\text {th }}$ ). For each destination, a total of 30 photographs were used for the analysis of their "projected image". Here, duplicate photographs were included for analysis because their repetition is due to DMO's intention to publish a specific photograph twice. Nevertheless, this was only the case for one photograph posted under www.visitalesund-geiranger.com.

\subsection{Categorisation}

A list of categories and possible values was constructed to systematise the analysis of photographs. First, a preliminary list based on the literature was developed. Then, this list was evaluated by three researchers individually. Last, comments and impressions were used to make the necessary improvements. The list contains items that have proven to be relevant in previous studies (Table A1), as well as elements that were used in the survey among travellers of the "Geirangerfjord" and "Ncerøyfjord". The latter were included to tailor the variables and categories to these destinations and make the categorisation scheme contextually relevant.

Table A2 in the Appendix provides an overview of variables, categories and values that were used to systematise the analysis of photographs. The categorisation scheme includes nine variables, each with different number of categories (98 categories in total). Five variables describe the presence of people and who/how many they are; another variable tells whether the photograph was taken during the day/night; the other three variables indicate the photograph's genre, the elements shown, and the activities captured in the photographs. Categories of the first seven variables are mutually exclusive. This is not the case for the two last variables for which several categories can be selected. The title of the photographs was also taken into account, to both identify specific attractions which were photographed and to help categorise the photographs. We assumed that the title contains important information about what the photograph illustrates, especially for those who are not familiar with the destination (which is often the case among people seeking information as part of their travel planning).

This categorisation was used to analyse selected photographs projecting both "perceived" and "projected" image of the destinations under investigation. All pictures 
were categorised by a researcher who - when necessary - consulted the other two researchers, to the aim being to reduce subjective bias and ensure consistency. With this in mind, it was important to have predefined descriptions of genres, as selecting the genre was challenging, especially when key elements of various genres were combined in a single photograph.

We would like to draw the reader's attention to two issues when interpreting these results. First, a large share of DMOs photographs (27\%) seems to be "staged". This term is used by Stepchenkova and Zhan (2013) to differentiate pictures capturing "staged" performances from those representing the "way of life", i.e. traditional or modern activities that show natural (real) living conditions of local people. Second, certain landscapes classified as natural contained cultural elements, when these were either unrecognisable (e.g. due to the quality of the picture) or played a minor role in the picture compared to the natural surroundings. A photograph illustrating a natural landscape with a "vessel", which is not in focus, is classified as "natural landscape", although all the elements captured in the photograph, including the "vessel", are also registered and included in the results

\section{Results}

Photographs were analysed during the fall (weeks 48 and 49) of 2015. In the following we present main results by destination. In the discussion section, we also compare results across destinations.

\subsection{Geirangerfjord}

\subsubsection{The presence of people and time of day}

The analysis shows that almost three quarters (73\%) of photographs laid out by the DMO of the "Geirangerfjord" contains people. This share is much lower among photographs posted by Instagram users (21\%). Photographs posted by the DMO represent mostly couples (33\%) followed by individuals (20\%) and groups of three to nine persons $(17 \%)$. Few of them show children (3\%). Photographs posted by Instagram users that represent people contain mostly individuals $(18 \%)$. None of these photographs show groups of 3 or more people, and children are not represented.

In over one third (37\%) of the photographs posted by the DMO, it is not clear whether those depicted are tourists or locals. This is because many of these photographs (27\%) show "staged" performances. Selfies are absent among photographs posted by the DMO and rare (1\%) among user-generated photographs. The majority of DMO photographs are close-ups (47\%). In 13\% of the DMO pictures, persons are depicted at a medium distance from the camera. In user-generated photographs these shares are, respectively, $13 \%$ and $4 \%$.

All pictures were captured during the day.

\subsubsection{Genre}

Table 1 shows the distribution of photographs' genres posted by DMO and Instagram users (UGC) on the "Geirangerfjord". There are differences between the dominating 
genres of "projected" (DMO) and "perceived" (UGC) images. The predominant genre among photographs posted by the DMO is "adventure/outdoor" (40\%), but for usergenerated pictures it is "natural landscape" (38\%). Although "adventure/outdoor" photographs are framed within nature, pictures posted by the DMO provide a more "active" image of the "Geirangerfjord", while user-generated photographs focus on showing the "nature" itself.

"Cultural landscape" is the second largest genre of photographs posted by both DMO and Instagram users. This genre accounts for, respectively, $23 \%$ and $19 \%$ of the "projected" and "perceived" images. Nevertheless, these "cultural landscapes" are also often represented within natural settings. This is supported by the type of elements contained in the analysed pictures, as described below.

The third largest genre among photographs posted by the DMO is shared by "natural landscape" and "other culture loaded elements" (10\% each), while "cultural heritage buildings \& infrastructure" is not represented among DMO pictures. The rest (17\%) is equally distributed among five further categories. The share of user-generated pictures not pertaining the two largest genre categories is larger (43\%) and more fragmented among a larger number of genres. This is to be expected considering that the experiences and impressions among travellers vary from person to person.

\subsubsection{Elements}

Table 2 shows the similarities and differences of the elements in the photographs posted by the DMO and Instagram users. Note that these categories are not mutually exclusive, i.e. a picture can contain multiple items.

Natural elements predominate in both the DMO- and user-generated pictures. Unlike genres, the variety of elements is greater among photographs posted by the DMO than among user-generated photographs. This may be because - as previously indicated - a relatively large proportion of DMO pictures seem to be staged (27\%). Such photographs show special elements such as "traditional clothing", "domesticated animals" and "festivals and rituals".

Buildings, road infrastructure and vessels are also frequently represented. The prevalence of these cultural or man-made elements may be explained by the fact that these elements are easier to identify than other items, such as "caves", "churches", "contemporary, large artistic installations", "museums and galleries", "amusement-parks, zoos, pool areas", "statues", "memorials", "restaurants" and "other food \& beverages", which were not found in any of the analysed pictures.

Special attractions/locations shown in the photographs posted by the DMO are "Flydalsjuvet" (3) and "Ørnesvingen" (2), while user-generated photographs show the "Trollstigen" (6) and "Trollstigen" plateau (4). Further attractions depicted in usergenerated pictures are "the-seven-sisters' waterfall" (1), "Flydalsjuvet" (1), "Knuten" (1), "Union Bath \& Spa" (1) and "Vasterås Gård" (1). The "Geiranger" camping location also appears in three user-generated and one of the DMO photographs.

\subsubsection{Activities}

Table 3 shows the type of activities portrayed in the photographs posted by both the DMO and Instagram users. $80 \%$ of the DMO photographs contained some activity. This share is reduced almost by half ( $41 \%)$ in the case of user-generated photographs. This 
reflects to some extent the distribution of genres described above (DMO photographs are more focused on "adventure/outdoor" than user-generated photographs). The most commonly depicted activities are "fjord safari \& cruise" among both groups of pictures. Several activities are not represented at all. These included "wilderness camping", "popular walk \& sports competitions", "traditional games", "volunteer work", "domestic work" and "shopping".

Table 1 Genre of photographs posted by DMO $(n=30)$ and Instagram users (UGC) $(n=85,90)$ on the Geirangerfjord and Nærøyfjord (in percent)

\begin{tabular}{lcccc}
\hline & \multicolumn{2}{c}{ Geirangerfjord } & \multicolumn{2}{c}{ Ncerøyfjord } \\
\hline & DMO & $U G C$ & DMO & UGC \\
\hline Natural landscape & 10 & 38 & 17 & 28 \\
Cultural/cultivated landscape & 23 & 19 & 10 & 29 \\
Town/urban landscape & 0 & 0 & 0 & 1 \\
Transport (infrastructure) & 3 & 7 & 17 & 12 \\
Tourism and commercial products \& facilities & 3 & 1 & 20 & 1 \\
Contemporary distinctive buildings \& & 0 & 5 & 3 & 3 \\
infrastructure & 0 & 5 & 3 & 1 \\
Cultural heritage buildings \& infrastructure & 10 & 0 & 3 & 0 \\
Other culture-loaded elements & 3 & 5 & 10 & 13 \\
Portrait \& people & 3 & 0 & 0 & 0 \\
Way of Life & 0 & 5 & 17 & 2 \\
Still life & 0 & 2 & 0 & 2 \\
Wildlife \& plants & 3 & 1 & 0 & 2 \\
Grazing animals & 40 & 7 & 0 & 4 \\
Adventure/outdoor & 0 & 6 & 0 & 0 \\
Other & & & & \\
\hline
\end{tabular}

Table 2 Elements illustrated in photographs posted by DMO $(n=30)$ and Instagram users (UGC) $(n=85,90)$ on the Geirangerfjord and Nærøyfjord (in percent)

\begin{tabular}{lcccc}
\hline & \multicolumn{3}{c}{ Geirangerfjord } & \multicolumn{2}{c}{ Narøyfjord } \\
\hline & $D M O$ & $U G C$ & DMO & UGC \\
\hline Fjord \& mountain & 43 & 48 & 27 & 49 \\
Lakes, surface waters & 63 & 62 & 33 & 61 \\
Waterfalls and rivers & 37 & 21 & 23 & 30 \\
Patches of snow \& glaciers & 60 & 58 & 30 & 40 \\
Forest \& natural vegetation & 87 & 85 & 80 & 89 \\
Mountain peaks \& mountain terrain & 80 & 82 & 57 & 86 \\
Shoreline \& beaches & 53 & 60 & 30 & 57 \\
Wildlife & 3 & 1 & 0 & 2 \\
Plants \& grass & 33 & 19 & 37 & 31 \\
Viewing platforms & 13 & 6 & 10 & 6 \\
\hline
\end{tabular}


Do visitors gaze and reproduce what destination managers wish to commercialise? 305

Table 2 Elements illustrated in photographs posted by DMO $(n=30)$ and Instagram users (UGC) $(n=85,90)$ on the Geirangerfjord and Nærøyfjord (in percent) (continued)

\begin{tabular}{lcccc}
\hline & \multicolumn{2}{c}{ Geirangerfjord } & \multicolumn{2}{c}{ Narøyfjord } \\
\hline & $D M O$ & $U G C$ & $D M O$ & $U G C$ \\
\hline Technical installations & 0 & 1 & 0 & 7 \\
Historic heritage & 7 & 5 & 17 & 14 \\
Museums \& galleries & 0 & 0 & 3 & 0 \\
Farms & 7 & 6 & 0 & 2 \\
Amusement-parks, zoos, pool areas & 0 & 0 & 23 & 0 \\
Statues & 0 & 0 & 13 & 2 \\
Accommodation sites & 7 & 4 & 13 & 1 \\
Other foods \& beverages & 0 & 0 & 3 & 1 \\
Shopping facilities & 0 & 1 & 0 & 0 \\
Other/diverse buildings & 30 & 24 & 43 & 39 \\
Small art \& cultural objects & 3 & 0 & 3 & 1 \\
Flags & 7 & 0 & 3 & 1 \\
Tourist signs & 7 & 2 & 0 & 1 \\
Domesticated animals & 13 & 2 & 7 & 1 \\
Festivals \& rituals & 3 & 0 & 3 & 0 \\
Staged performances & 27 & 0 & 10 & 0 \\
Traditional clothing & 13 & 0 & 3 & 1 \\
Road vehicles & 13 & 7 & 7 & 3 \\
Road infrastructure & 30 & 34 & 20 & 20 \\
Rail(ways) & 0 & 0 & 13 & 16 \\
Cruise & 23 & 13 & 13 & 8 \\
Ferries & 70 & 6 & 13 & 9 \\
Smaller boats & 13 & 7 & 8 \\
Ports & & 5 & 7 & 1 \\
Other & 13 & 23 & 18 \\
\hline & & 16 & \\
\hline
\end{tabular}

Table 3 Activities illustrated in photographs posted by DMO $(n=30)$ and Instagram users (UGC) $(n=85,90)$ on the Geirangerfjord and Nærøyfjord (in percent)

\begin{tabular}{lcccc}
\hline & \multicolumn{2}{c}{ Geirangerfjord } & \multicolumn{2}{c}{ Ncerøyfjord } \\
\hline None & $D M O$ & $U G C$ & $D M O$ & $U G C$ \\
Walking/hiking, climbing & 20 & 59 & 50 & 44 \\
Biking & 13 & 4 & 0 & 6 \\
Wilderness camping & 7 & 2 & 0 & 0 \\
Other land sport activities & 0 & 0 & 0 & 0 \\
Kayaking, rafting, paddling, boat & 3 & 1 & 0 & 0 \\
Fishing & 0 & 1 & 0 & 0 \\
\hline
\end{tabular}


Table 3 Activities illustrated in photographs posted by DMO $(n=30)$ and Instagram users (UGC) $(n=85,90)$ on the Geirangerfjord and Nærøyfjord (in percent) (continued)

\begin{tabular}{lcccc}
\hline & \multicolumn{2}{c}{ Geirangerfjord } & \multicolumn{2}{c}{ Ncerøyfjord } \\
\hline & $D M O$ & $U G C$ & $D M O$ & $U G C$ \\
\hline Fjordsafari \& cruise & 17 & 16 & 17 & 13 \\
Other activities on the fjord/rivers & 3 & 0 & 0 & 0 \\
Popular walk \& sports competitions & 0 & 0 & 0 & 0 \\
Gazing, photographing & 7 & 7 & 10 & 7 \\
Eating, drinking & 0 & 2 & 3 & 2 \\
Reading, writing \& board games & 3 & 0 & 3 & 0 \\
Dancing \& playing music & 3 & 0 & 3 & 0 \\
Traditional games & 0 & 0 & 0 & 0 \\
Volunteer work & 0 & 0 & 0 & 0 \\
Domestic work & 0 & 0 & 0 & 0 \\
Shopping & 0 & 0 & 0 & 0 \\
Other & 23 & 11 & 23 & 34 \\
\hline
\end{tabular}

\subsection{Ncerøyfjord}

\subsubsection{The presence of people and time of day}

The proportion of photographs that show people is very similar in DMO- $(40 \%)$ and user-generated pictures (34\%). In DMO photographs containing people, representations of couples are most frequent $(17 \%)$, followed by representations of individuals $(10 \%)$ and groups of 10 or more people (10\%), while minor groups (of three to nine persons) are less frequent $(3 \%)$. Few of the pictures show children $(7 \%)$. In user-generated photographs depicting people, representations of individuals are most frequent $(26 \%)$ while couples (2\%) and groups of three to nine persons $(7 \%)$ are far less frequent. None of the pictures show children.

Again, it was not easy to identify who is depicted, particularly for the DMO pictures $(23 \%)$. There are no selfies among photographs posted by the DMO and they are seldom among those posted by Instagram users $(3 \%)$. In photographs in which persons are depicted, these are relatively close to the camera in both the DMO- $(23 \%)$ and usergenerated pictures (21\%). 13\% of the DMO photographs portray also people far away from the camera.

Most photographs were taken during the day. This is the case for both the DMO$(97 \%)$ and user-generated pictures (91\%).

\subsubsection{Genre}

Table 1 shows the distribution of the DMO- and user-generated photographs of "Ncerøyfjord". User-generated pictures are generally spread across several genres, but over half of them belong to one of the two largest categories. Conversely, the number of genres of DMO photographs is lower but their distribution more balanced. Dominating genres among DMO pictures are "tourism and commercial products and facilities" 
(20\%), followed by "natural landscape", "transport" and "still life" (17\% each), and "cultural landscape" and "portrait/people" (10\% each). None of the DMO pictures were classified as "town/urban landscapes", "way of life", "wildlife \& plants", "grazing animals" or "adventure/outdoor".

More than half of the user-generated photographs were classified as either "cultural landscapes" $(29 \%)$ or "natural landscapes" $(28 \%)$. These categories are followed by "portrait \& people" (13\%) and "transport" (12\%). The rest is distributed among eight further genres. There are quite large differences in the shares of pictures pertaining the genres of "tourism and commercial products and facilities", "still life", "natural landscape" and "cultural landscape".

\subsubsection{Elements}

Table 2 summarises the share of DMO- and user-generated photographs containing certain elements. The elements of the DMO pictures largely reflect the genre of images described above. Certain elements such as "caves", "churches", "contemporary, large artistic installations", "memorials", "restaurants", "shopping facilities" and "airplanes and airports" are again not illustrated. Photographs posted by both the DMO and Instagram users are dominated by natural elements, while cultural elements are present to a greater extent by DMO than by user-generated photographs.

Specific attractions are also depicted in DMO pictures. These include the "Fretheim" Culture Park (7), "Flåmsbana" (4), "Bakka Stova" (2), "Stegastein" (2), "Heimly Pensionat" (2), "Fretheim" hotel (1) and "Stahlheim" viewpoint (1). User-generated photographs portray attractions such as the "Flåmsbana" (11), "Stegastein" (4), "Myrdal" (3), "Kjøsfossen" (2), "Brekkefossen" (2), "Storehouse" (1) and "Rallarveggen" (1).

\subsubsection{Activities}

Table 3 illustrates the type of activities captured in the photographs of "Ncerøyfjord" posted by both the DMO and Instagram users. Half of the pictures posted by the DMO show activities while this share is slightly higher for user-generated pictures $(56 \%)$. Dominant activities among both groups were "fjord safari \& cruise" and "gazing \& photographing". Several of the activities of our list (Table A2) are not represented at all, e.g. "biking", "kayaking, rafting, canoeing, boat", "fishing" and "other land or water related sports activities" as well as further activities were neither found in photographs of the "Geirangerfjord".

\section{Discussion}

According to our analysis using the categorisation scheme described, there are differences between the "projected image" depicted by DMO photographs and the "perceived image" depicted by user-generated photographs.

People are depicted more often in pictures projected by the "Geirangerfjord" DMO than in pictures generated by Instagram users, and the former also display groups of two people more often than user-generated pictures do. But the most striking difference is that the "Geirangerfjord" DMO focuses on projecting an image in which adventure and outdoor activities are exalted, even though this may happen through a somewhat "staged" 
photography. This is understandable as selling travel experiences has become very important (Bartley and Hancock, 2008). However, some researchers insist on the importance of projecting images based on reality to facilitate satisfaction with the visitation experience (O'Leary and Deegan, 2005; Beerli and Martin, 2004). Incongruity between the destination image before and during/after visitation may negatively affect satisfaction levels and, thus, WOM and intention to revisit (O'Leary and Deegan, 2005). Simulations can invite visitors to seek new experiences but they need to have some "realness", if they are to produce authentic experiences (Bartley and Hancock, 2008). Thus, "staged" pictures could be detrimental for the destination. In contrast, the most frequent genre displayed in user-generated photographs are natural landscapes. Cultural landscapes are an important genre in both "projected" and "perceived" images. Elements and activities captured in the analysed photographs reflect these genres.

In the case of "Ncerøyfjord", the proportion of photographs that show people is very similar in "projected" and "perceived" images. At this destination, "tourism and commercial products \& facilities" are the dominating genre among pictures commercialised by the DMO, closely followed by "natural" and "cultural landscapes". The later are the dominating genres among user-generated photographs, while the genre of photographs posted by the DMO is more varied. This could be interpreted as an effort by the DMO to commercialise the wide range of attractions the destination has to offer. Although the most frequent element display in user-generated photographs is the "Fläm" railway, half of the user-generated pictures show "fjord \& mountains", this share being significantly lower among DMO photographs.

Results indicate that Instagram users capture and post their own photographic impressions of the "Geirangerfjord" and "Ncerøyfjord". O'Leary and Deegan (2005) argue that marketers rarely assess whether the attributes contained in messages are important to visitors. Assuming that user-generated photographs contain those elements in which travellers are most interested, one could question whether the pictures used by the DMOs investigated are likely to appeal to their audience and, thus, support the promotion of the destination. Scott et al. (2017, p.31) argue that digital technology has changed the marketing process from what "resembled a broadcast lecture to [something] more akin to a conversation". However, like other researchers (Bibelheimer, 2014; Hays et al., 2013; Munar, 2012) they argue that such "conversation" is far limited in practice, as DMOs fail to capitalise on the opportunities that digital technology and social media offer, to engage with stakeholders in the joint creation of destination image. Researchers (Cabiddu et al., 2014; Alam and Diamah, 2012) urge DMOs to engage in dialogue with social media users, and offer spaces that allow for more dynamic communication in their traditional websites (Hernández-Méndez et al., 2015).

The impact of social media and e-WOM does not have to be negative for the DMO. An analysis of the Facebook page of the Australian DMO illustrates that user-generated pictures can contribute to showcase the beauty and diversity of a destination as well as to prompt other "fans" to upload their pictures (Alam and Diamah, 2012). UGC can be used, among other, to improve negatively valued aspects, understand how different markets perceive different products, and project a desired image (Camprubí et al., 2013). Best practices reported by Királová and Pavlíčeka (2015), Latorre-Martínez et al. (2014) and Alam and Diamah (2012) illustrate how successful social media strategies can help destinations to increase the number of visitors and trigger UGC that positively influences destination image. 
A comparison across destinations is also interesting. Contrarily to "Geirangerfjord", the DMO of "Ncerøyfjord" does not seem interested in projecting an "adventure/outdoor" image of itself. Instead, it focuses on marketing "tourism and commercial products" such as the "Fretheim Culture Park" and the "Fläm" railway. This could be indicative of a strategy used by these destinations to commercialise other attractions in an attempt to extend travellers' length-of-stay. Based on our analysis, visitors seem to be aware of that. Although travellers at both destinations reproduce natural elements in their photographs, Instagram users posting on "Flåm" images are more interested in historic-cultural elements.

The method we used to select photographs for the analysis of the "perceived image" illustrates the importance of using appropriate "hashtags" when posting and searching travel information in social media. This is especially relevant for Norway and the Scandinavian region, whose alphabet includes letters which are not common elsewhere. A visitor planning her trip to "Flåm" would probably find much irrelevant information in social media, if she searches for "flam". This can be confusing and might be detrimental for the promotion of the destination. DMOs' social media strategies to promote sharing travel experiences under designated "hashtags" can reduce this risk.

One advantage of focusing on photography is that one can avoid the challenges linked to translation when analysing the many languages of written UGC (Steen Jacobsen, 2007). Yet, analysing photographs poses also important challenges. Among them, it was difficult to identify who is the subject depicted in the pictures, and this in turn influenced the choice of genre. If subjects were locals, pictures could have been representing the "way of life" of local communities, i.e. sociocultural values that the visitor can contemplate or in which they can actively participate. However, if the subjects depicted in the photograph were tourists, photographs could have been depicting "adventure/outdoor" activities, which visitors could perform and may (or not) be part of the traditional way of life of local communities. Similarly, was challenging to categorise buildings depicted on photographs, especially those framed in landscapes. Unless the picture was accompanied by an explanatory text, it was at times difficult to judge whether a building was a museum, an accommodation or a private dwelling.

An inevitable further limitation of the study is the element of subjectivity. We have attempted to reduce this limitation by including descriptions of variable values in the categorisation scheme as well as by consulting researchers to ensure consistency during the analysis. Techniques that employ software could further reduce this subjectivity by limiting the individual choices made by the researcher and increasing the systematic analysis of UGC. For this, further research on destination image could build on existing studies employing harvesting and automated analysis of UGC (Garay Tamajón and Cánoves Valiente, 2015; Cheng and Edwards, 2015; Johnson et al., 2012).

Last, many of the categories used in our scheme (Table A2) were not found in selected photographs, raising the question of whether they are relevant for this specific region. A more thorough study could combine qualitative methods to improve the adequacy of the categorisation scheme for Norwegian destinations.

\section{Conclusion}

This study has constructed a categorisation scheme for conducting photography-based image analysis of destinations. Assessing whether the destination's image perceived 
by tourists emulate (or not) the commercial image that destination management organisations (DMOs) are interested to project is relevant for both tourism researchers and practitioners, especially given the uptake of social media. Our results are in line with those from Månsson (2011), Choi et al. (2007) and Jenkins (2003), who also found differences between "projected" and "perceived" images. Although it is not possible to generalise the findings of this research, the results indicate that the "circle of representation" may no longer be "hermeneutic", at least in the case of the two Norwegian destinations studied here. This can be seen as positive, since hermeneutic narratives can constrain visitors' choices and reduce experiential authenticity (Bartley and Hancock, 2008). Yet, it would be interesting to assess how these images have developed and will develop longitudinally (especially considering the attention these two destinations have lately received due to the increasingly negative image of cruise tourism).

Essentially we see three streams for future research: (i) investigate whether our findings can be generalised to the whole population of travellers; (ii) assess the implications for the decision-making process; and (iii) understand how disruption of the circle of representation may affect the role of DMOs. Regarding the first stream, in order to know whether we can generalise findings, further research is required to improve our understanding on what differentiates users of photograph-based social media from nonusers. By analysing user-generated photographs shared in social media one can investigate how users experience the places they visited (Steen Jacobsen, 2007). Yet, we know little about who these users are and the mechanisms that influence which pictures they select to share online. Syed-Ahmad et al. (2009) argue that the opinions and norms of people that are perceived as important to the sender, of behaviourally relevant groups, and of society, may each influence the posting of pictures, depending on the type of openness of the online site. Lo et al. (2011) conclude that younger users may post pictures as a vehicle of self-representation, while sharing by older users may tend more to resemble the offline sharing of photographs. As Aalen (2012, pp.26-27) points out, massive adoption of social media does not necessarily mean social media is actively used. Moreover, usage patterns vary across different types of social media (Aalen, 2012; Beckendorff et al., 2014).

Regarding the second research stream we envisage, the utility of UGC for travellers needs to be assessed in order to investigate the implications of the findings for the decision-making process of where to travel. Even if user-generated photography breaks the "hermeneutic circle of representation" and diminishes the control exerted by DMOs, there is still uncertainty about its real impact in the planning and decision-making process. Some studies show that UGC-driven websites are more trustworthy (Gretzel, 2007 ) and carry greater weight with travellers than offline sources and web 1.0-sources (Llodrà-Riera et al., 2015). However, there are also studies showing that traditional sources of information are more influential than e-WOM (Steen Jacobsen and Munar, 2012; Hernández-Méndez et al., 2015). Credibility varies depending on the type of social media (Munar and Jacobsen, 2013); the characteristics of the sender (e.g. appearance), message (e.g. relevance, enjoyment, readability) and receiver (e.g. experience); and the sender-receiver relationship (e.g. trust) (Beckendorff et al., 2014; Liu and Park, 2015; Del Chiappa et al., 2015; Filieri et al., 2015; Aalen, 2012). Beerli and Martin (2004) found that "organic" information - as opposed to "induced" information - significantly influences factors determining the cognitive aspect of destination image. 
Regarding the third research stream, in order to assess the implications for DMOs of the circle of representation being less hermeneutical, further research needs to investigate how DMOs adapt (if they do at all), and which organisational, professional and operational changes this may imply. What kind of challenges do they meet when coping with the rise of UGC? Do they effectively manage it to capitalise on it? What barriers prevent them from doing so? What type of knowledge and skills would professionals working in DMOs need to provide? What would their role be? How would they manage to coordinate the system of tourism actors at the destination that, ultimately, provide the tourism experience?

Finally, we would like to point out a trend that will have implications for future research and destination image analysis. On one hand, tourism service providers are entering social media and offering spaces to allocate UGC in their till now traditional web 1.0 websites. On the other hand, one could also argue that, empowered by web 2.0, travellers' perceived images turn into projected images of their own. Thus, the differentiation of "perceived" and "projected" image may become blurred and needs, thus, to be revised.

\section{Acknowledgements}

This study has been funded by the Research Council of Norway, the Regional Research Fund in West Norway (RFFVEST), project 245325 "Besøksforvaltning og lokalsamfunnsutvikling" [Visitor management and local community development], and the Institute of Transport Economics".

\section{References}

Aalen, I. (2012) En kort bok om sosiale medier, Fagbokforlaget, Oslo.

Alam, S.L. and Diamah, A. (2012) Understanding user participation in Australian Government Tourism Facebook Page', 23rd Australasian Conference on Information Systems, 3-5 December, Geelong.

Baloglu, S. and McCleary, K.W. (1999) 'A model of destination image formation', Annals of Tourism Research, Vol. 26, No. 4, pp.868-897.

Bartley, E.A. and Hancock, J.E. (2008) 'Virtual reconstructions as destination tourism?' International Journal of Digital Culture and Electronic Tourism, Vol. 1, Nos. 2/3.

Beckendorff, P., Sheldon, P. and Fesenmaier, D. (2014) Tourism Information Technology, CABI Tourism texts, September.

Beerli, A. and Martin, J.D. (2004) 'Factors influencing destination image', Annals of Tourism and Research, Vol. 31, pp.657-681.

Bibelheimer, A.M.S. (2014) Social Media Marketing. A case study of VisitDenmark in Hamburg, Internship Report - 9th Semester MA Tourism at Aalborg University, Copenhagen.

Bonini, E. (2008) 'Building virtual cultural heritage environments: the embodied mind at the core of the learning processes', International Journal of Digital Culture and Electronic Tourism, Vol. 1, Nos. 2/3.

Cabiddu, F., Carlo, M. and Piccoli, G. (2014) 'Social media affordances: enabling customer engagement', Annals of Tourism Research, Vol. 48, pp.175-192. 
Camprubí, R., Guia, J. and Comas, J. (2013) 'The new role of tourists in destination image formation', Current Issues in Tourism, Vol. 16, No. 2, pp.203-209.

Chen, F.-W., Guevara Plaza, A. and Alarcón Urbistondo, P. (2016) 'Automatically extracting tourism-related opinion from Chinese social media', Current Issues in Tourism, DOI: $10.1080 / 13683500.2015 .1132196$.

Cheng, M. and Edwards, D. (2015) 'Social media in tourism: a visual analytic approach', Current Issues in Tourism, Vol. 18, No. 11, pp.1080-1087.

Choi, S., Lehto, X.Y. and Morrison, A.M. (2007) 'Destination image representation on the web: content analysis of Macau travel related websites', Tourism Management, Vol. 28, pp.118-129.

Crompton, J.L. (1979) 'An assessment of the image of Mexico as a Vacation destination and the influence of geographical location upon that image', Journal of Travel Research, Spring.

Del Chiappa, G., Lorenzo-Romero, C. and Alarcón-del-Amo, M.C. (2015) 'Profiling tourists based on their perceptions of the trustworthiness of different types of peer-to-peer applications', Current Issues in Tourism, DOI: 10.1080/13683500.2015.1077208.

Dybedal, P. (2017) Besøksforvalting og lokalsamfunnsutvikling $i$ verdensarvområdene $i$ Norøyfjorden og Geirangerfjorden, Verdiskapingsanalyse, 4155 Besøksforvaltning og lokalsamfunnsutvikling.

Filieri, R., Alguezaui, S. and McLeay, F. (2015) 'Why do travelers trust TripAdvisor? Antecedents of trust towards consumer-generated media and its influence on recommendation adoption and word of mouth', Tourism Management, Vol. 51, pp.174-185.

Garay Tamajón, L. and Cànoves Valiente, G. (2015) 'Barcelona seen through the eyes of TripAdvisor: actors, typologies and components of destination image in social media platforms', Current Issues in Tourism, DOI: 10.1080/13683500.2015.1073229.

Gennari, C. (2008) 'Digital photography and the digitalisation of foreign archives', International Journal of Digital Culture and Electronic Tourism, Vol. 1, No. 1, pp.100-107.

Gretzel, U. (2007) Online Travel Review Study. Role \& Impact of Online Travel Reviews, Laboratory for Intelligent Systems in Tourism, Texas A\&M University.

Gretzel, U. and Yoo, K-H. (2008) 'Use and impact of online travel reviews', Information and Communication Technologies in Tourism, DOI: 10.1007/978-3-211-77280-5_4.

Groves, D.L. and Timothy, D.J. (2001) 'Photographic Techniques and the Measurement of Impact and Importance Attributes on Trip Design: A case study', Loisir et Société/Society and Leisure, Vol. 24, No. 1, pp.311-317.

Hays, S., Page, S.J. and Buhalis, D. (2013) 'Social media as a destination marketing tool: its use by national tourism organisations', Current Issues in Tourism, Vol. 16, No. 3, pp.211-239.

Hernández-Méndez, J., Muñoz-Leiva, F. and Sánchez-Fernández, J. (2015) 'The influence of e-word-of-mouth on travel decision-making: consumer profiles', Current Issues in Tourism, Vol. 18, No. 11, pp.1001-1021.

Hunter, W.C. (2008) 'A typology of photographic representations for tourism: depictions of groomed spaces', Tourism Management, Vol. 29, pp.354-365.

Instagram (2017) Instagram. Instagrams hjelpesenter. Hvordan endrer jeg språkinnstillingene mine? Available online at: https://www.instagram.com/about (accessed on 28 April 2017).

Jenkins, O. (2003) 'Photography and travel brochures: the circle of representation', Tourism Geographies, Vol. 5, No. 3, pp.305-328.

Johnson, P.A., Sieber, R.E., Magnien, N. and Ariwi, J. (2012) 'Automated web harvesting to collect and analyse user-generated content for tourism', Current Issues in Tourism, Vol. 15, No. 3, pp.293-299.

Kádár, B. (2014) 'Measuring tourist activities in cities using geotagged photography', Tourism Geographies, Vol. 16, No. 1, pp.88-104. 
Kang, M. and Schuett, M.A. (2013) 'Determinants of sharing travel experiences in social media', Journal of Travel \& Tourism Marketing, Vol. 30, Nos. 1/2, pp.93-107.

Kaplan, A.M. and Haenlein, M. (2010) 'Users of the world, unite! The challenges and opportunities of Social Media', Business Horizons, Vol. 53, No. 1, pp.59-68.

Kavoura, A. and Stavrianea, A. (2015) 'Following and belonging to an online travel community in social media, its shared characteristics and gender differences', Procedia - Social and Behavioral Sciences, Vol. 175, pp.515-521.

Királ'ová, A. and Pavlíčeka, A. (2015) 'Development of social media strategies in tourism destination', Procedia - Social and Behavioral Sciences, Vol. 175, pp.358-366.

Kladou, S. and Mavragani, E. (2015) 'Assessing destination image: an online marketing approach and the case of TripAdvisor', Journal of Destination Marketing \& Management, Vol. 4, pp.187-193.

Larsen, J. (2006) 'Picturing Bornholm: producing and consuming a tourist place through picturing practices', Scandinavian Journal of Hospitality and Tourism, Vol. 6, No. 2, pp.75-94.

Latorre-Martínez, M.P., Iñíguez-Berrozpe, T. and Plumed-Lasarte, M. (2014) 'Image-focused social media for a market analysis of tourism consumption', International Journal of Technology Management, Vol. 64, No. 1, pp.17-30.

Leung, D., Law, R., van Hoof, H. and Buhalis, D. (2013) 'Social media in tourism and hospitality: a literature review', Journal of Travel \& Tourism Marketing, Vol. 30, Nos. 1/2, pp.3-22.

Li, X. and Wang, Y. (2011) 'China in the eyes of Western travelers as represented in travel blogs', Journal of Travel \& Tourism Marketing, Vol. 28, No. 7, pp.689-719.

Liu, Z. and Park, S. (2015) 'What makes a useful online review? Implication for travel product websites', Tourism Management, Vol. 47, pp.140-151.

Llodrà-Riera, I., Martínez-Ruiz, M.P., Jiménez-Zarco, A.I. and Izquierdo-Yusta, A. (2015) 'A multidimensional analysis of the information sources construct and its relevance for destination image formation', Tourism Management, Vol. 48, pp.319-328.

Lo, I.S., McKercher, B., Lo, A. and Rob Law, C.C. (2011) 'Tourism and online photography', Tourism Management, Vol. 32, pp.725-731.

MacInnis, D.J. and Price, L.L. (1987) 'The role of imagery in information processing: review and extensions', Journal of Consumer Research, Vol. 13, pp.473-491.

Marine-Roig, E. and Clavé, S.A. (2015) 'Tourism analytics with massive user-generated content: a case study of Barcelona', Journal of Destination Marketing \& Management, Vol. 4, No. 3, pp.162-172.

Markwell, K.W. (1997) 'Dimensions of photography in a nature-based tour', Annals of Tourism Research, Vol. 24, No. 1, pp.131-155.

Miguéns, J., Baggio, R. and Costa, C. (2008) 'Social media and tourism destinations: TripAdvisor case study', Advances in Tourism Research, November, pp.1-6.

Munar, A.M. (2012) 'Social media strategies and destination management', Scandinavian Journal of Hospitality and Tourism, Vol. 12, No. 2, pp.101-120.

Munar, A.M. and Steen Jacobsen, J.K. (2013) 'Trust and involvement in tourism social media and web-based travel information sources', Scandinavian Journal of Hospitality and Tourism, Vol. 13, No. 1, pp.1-19.

Månsson, M. (2011) 'Mediatized tourism', Annals of Tourism Research, Vol. 38, No. 4, pp.1634-1652.

O'Leary, S. and Deegan, J. (2005) 'Ireland's image as a tourism destination in France: attribute importance and performance', Journal of Travel Research, Vol. 43, February, pp.247-256.

Prestholdt, R. and Nordbø, I. (2015) 'Norwegian landscapes: an assessment of the aesthetical visual dimensions of some rural destinations in Norway', Scandinavian Journal of Hospitality and Tourism, Vol. 15, Nos. 1/2, pp.202-222. 
Santillán, V.L. (2010) 'La fotografía como creadora de la imagen de un destino turístico. Buenos Aires a través de sus tarjetas postales', PASOS. Revista de Turismo y Patrimonio Cultural, Vol. 8, No. 1, pp.71-82.

Scott, P., Scott, T., Stokes, P., Moore, N., Smith, S.M., Rowland, C. and Ward, T. (2017) 'The consumer journey in the digital age: the challenges faced by destination and place marketing agencies', International Journal of Digital Culture and Electronic Tourism, Vol. 2, No. 1, pp. $28-45$.

Steen Jacobsen, J.K. (2007) 'Use of landscape perception methods in tourism studies: a review of photo-based research approaches', Tourism Geographies, Vol. 9, No. 3, pp.234-253.

Steen Jacobsen, J.K. and Munar, A.M. (2012) 'Tourist information search and destination choice in a digital age', Tourism Management Perspectives, Vol. 1, pp.39-47.

Stepchenkova, S. and Zhan, F. (2013) 'Visual destination images of Peru: comparative content analysis of DMO and user-generated photography', Tourism Management, Vol. 36, pp.590-601.

Syed-Ahmad, S.F. (2011) Tourism, Communication \& Photography on Social Media, PhD Thesis, University of Western Australia.

Syed-Ahmad, S.F., Klobas, J.E. and Ismail, A.F. (2009) 'Pictures on the Web: Normative Photo Sharing with Friends and Travellers', ANZMAC 2009.

Urry, J. (1990) The Tourist Gaze. Leisure and Travel in Contemporary Societies, Sage Publications, London.

Xiang, Z. and Gretzel, U. (2010) 'Role of social media in online travel information search', Tourism Management, Vol. 31, pp.179-188.

Zhou, X., Xub, C. and Kimmons, B. (2015) 'Detecting tourism destinations using scalable geospatial analysis based on cloud computing platform', Computers, Environment and Urban Systems, Vol. 54, pp.144-153. 


\section{Appendix A}

Table A1 Overview of previous studies focusing on destination image

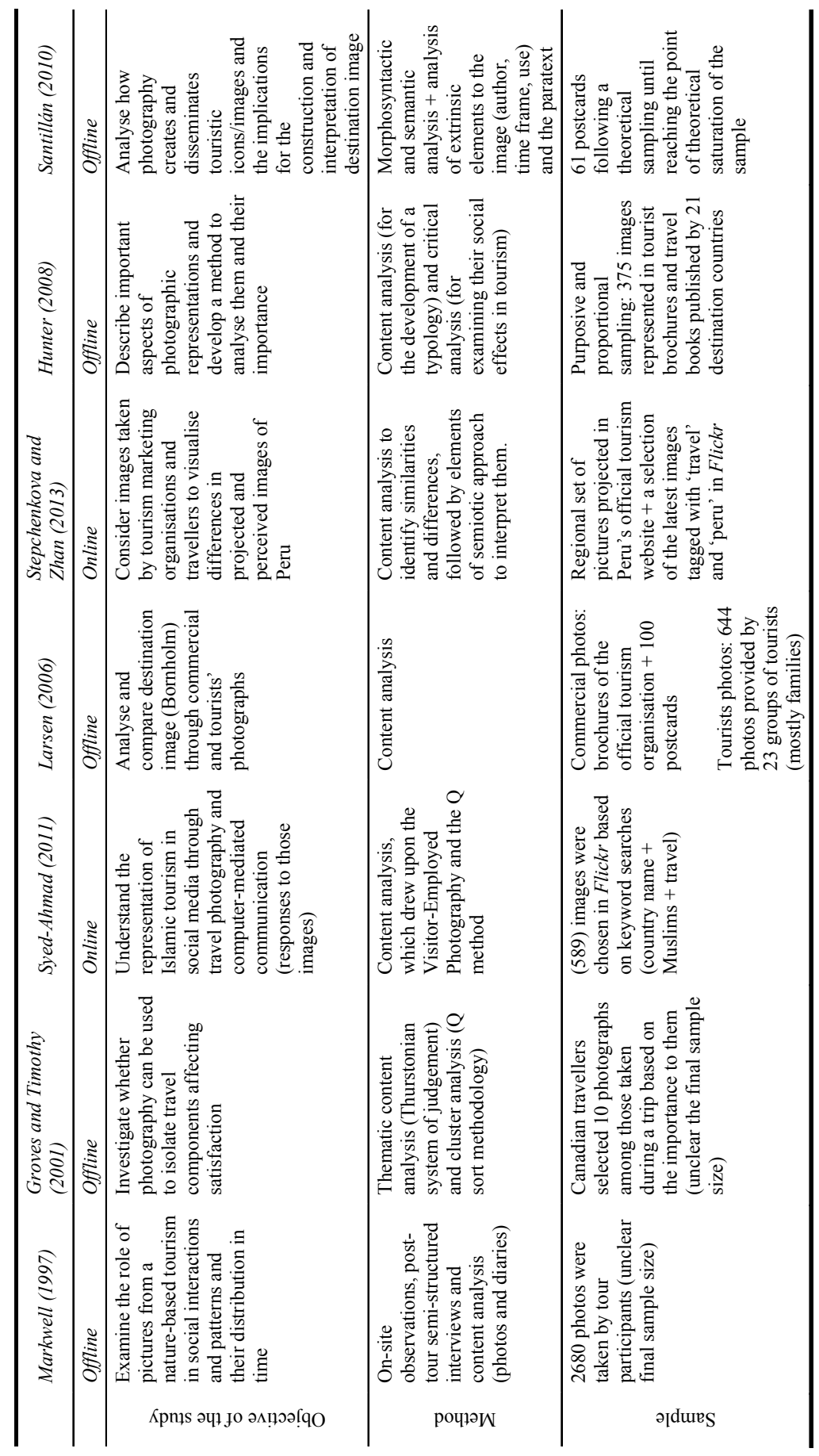


Table A2 Categorisation scheme used in the analysis of photographs

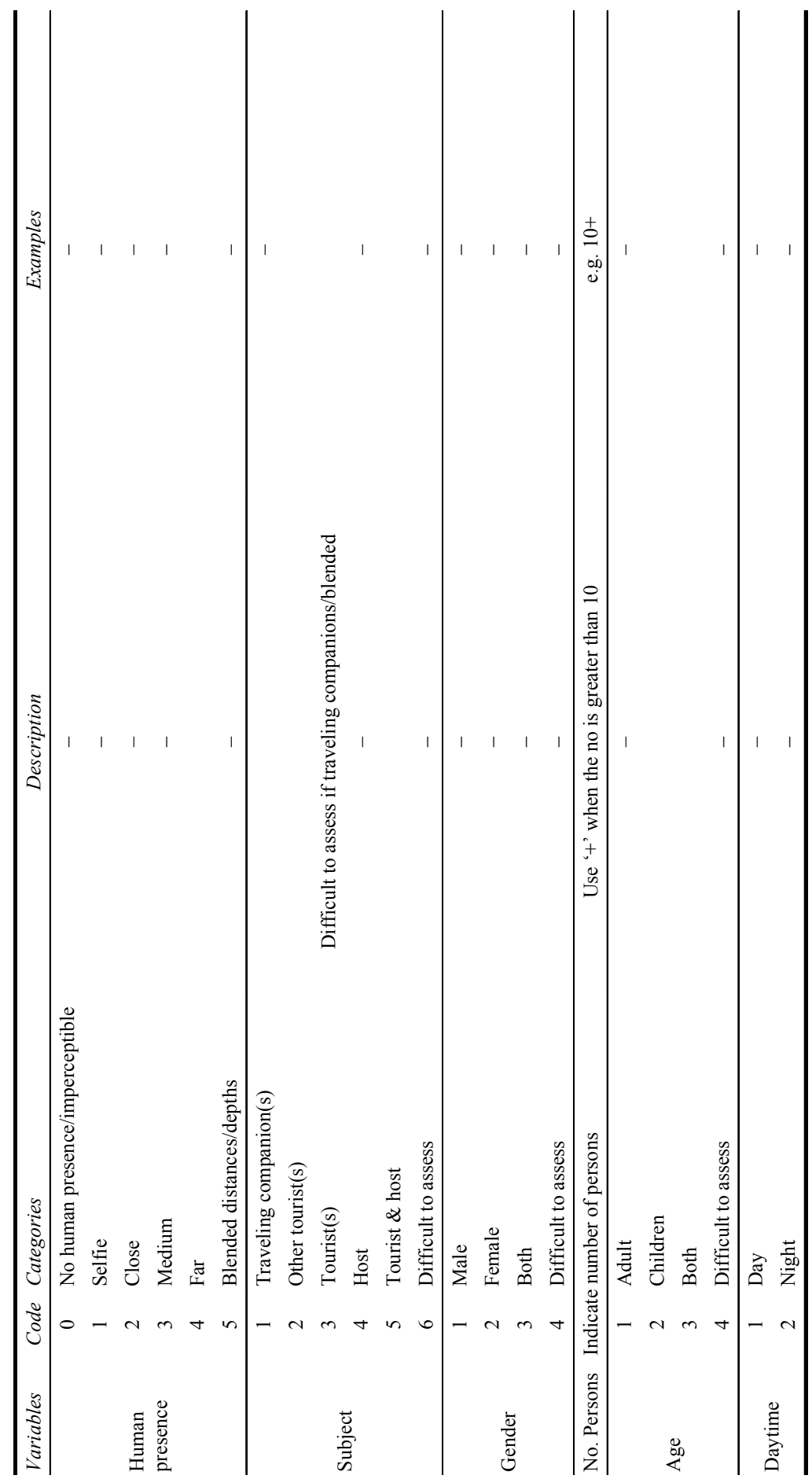


Table A2 Categorisation scheme used in the analysis of photographs (continued)

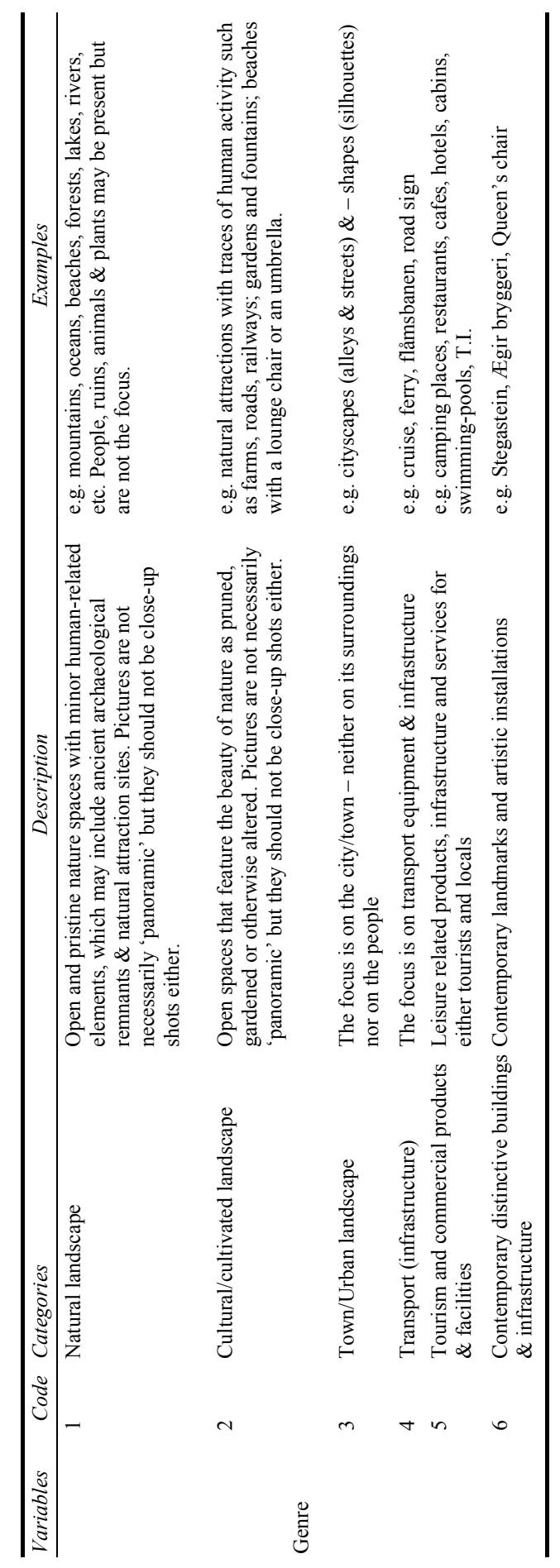


Table A2 Categorisation scheme used in the analysis of photographs (continued)

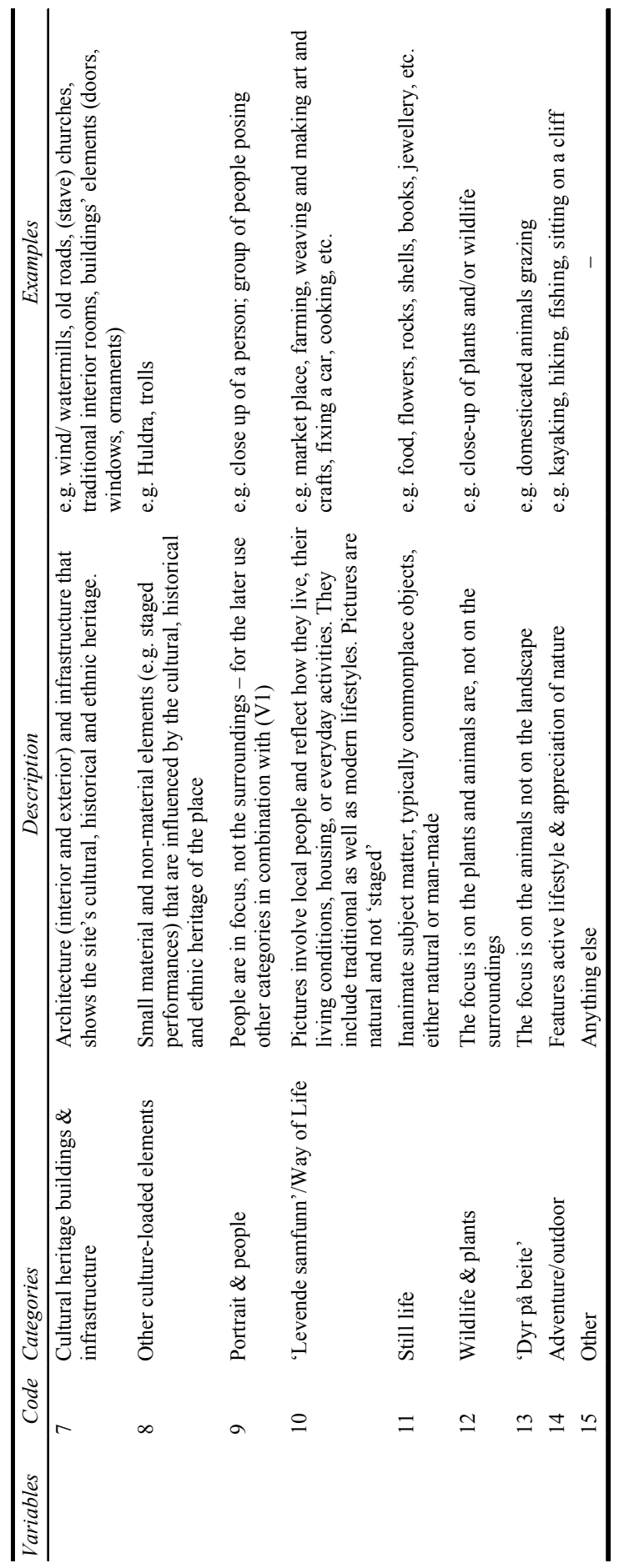


Do visitors gaze and reproduce what destination managers wish to commercialise? 319

Table A2 Categorisation scheme used in the analysis of photographs (continued)

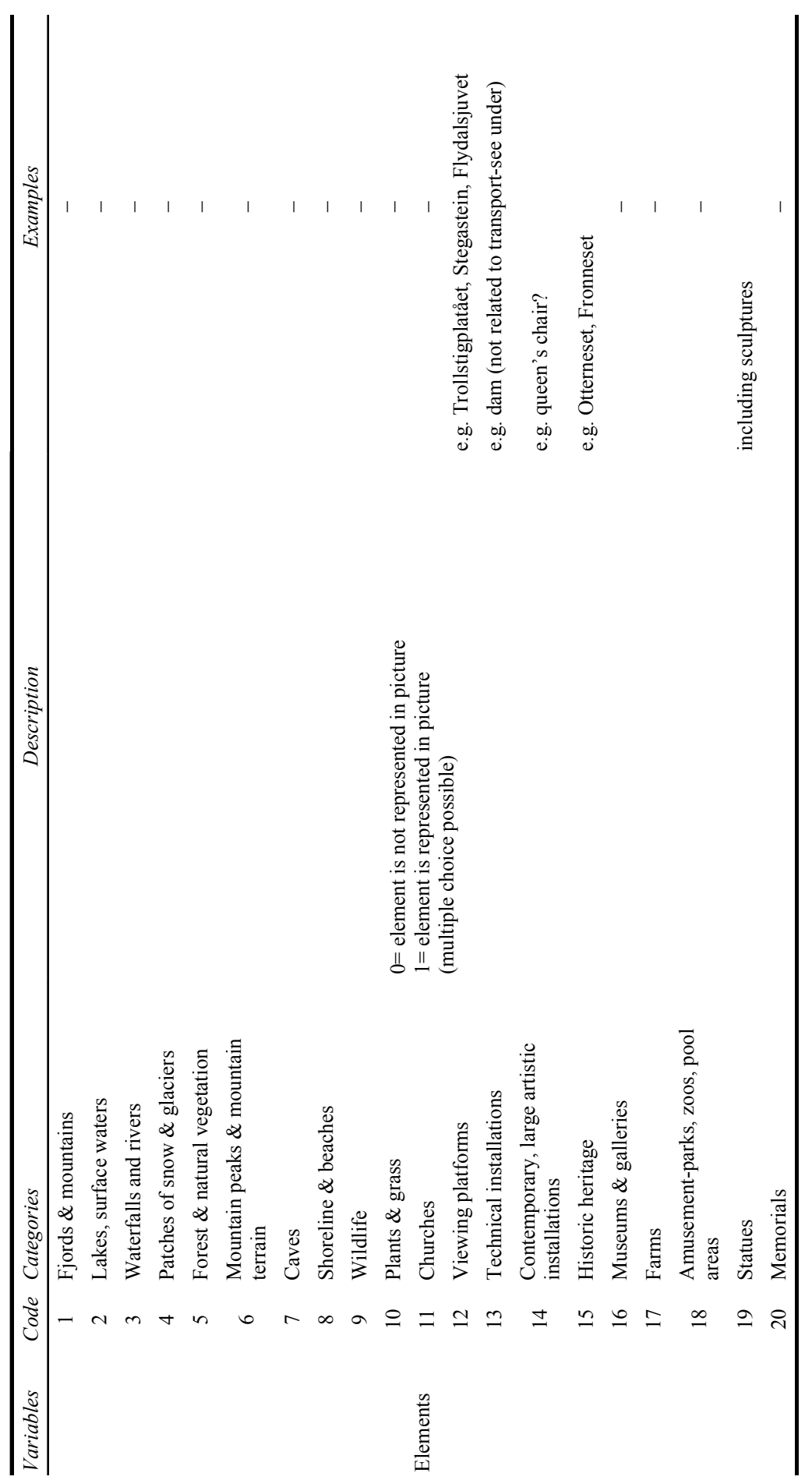


Table A2 Categorisation scheme used in the analysis of photographs (continued)

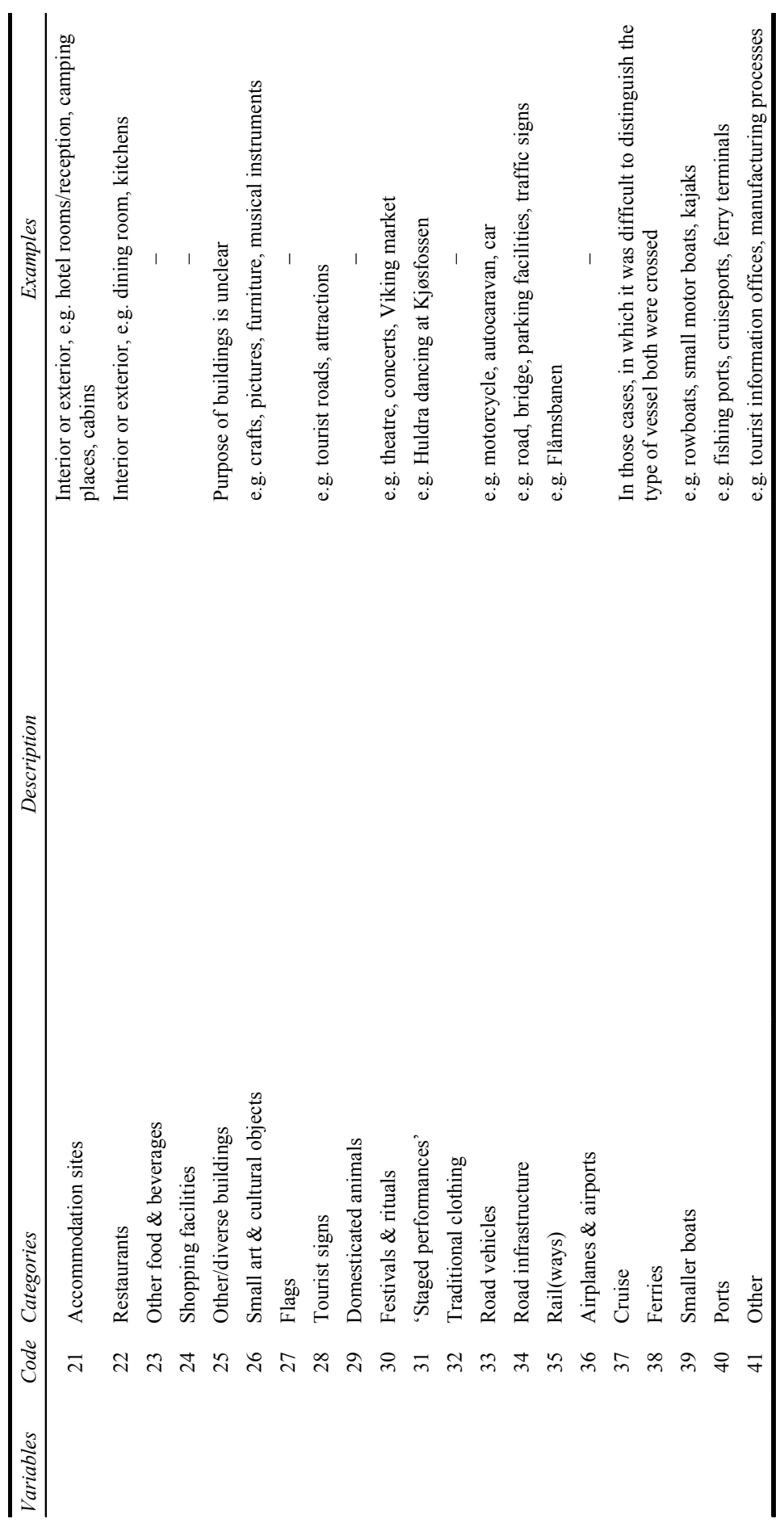


Do visitors gaze and reproduce what destination managers wish to commercialise? 321

Table A2 Categorisation scheme used in the analysis of photographs (continued)

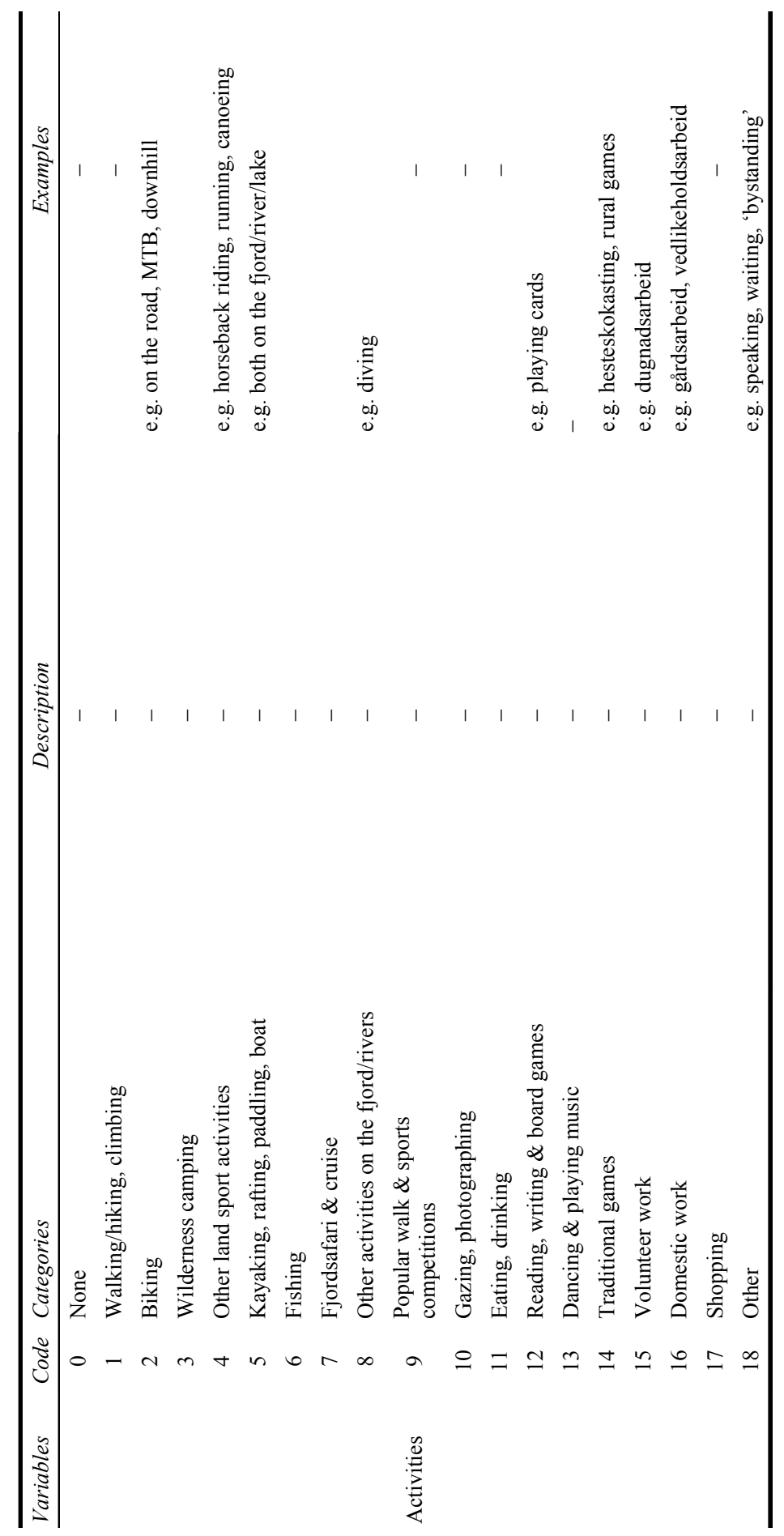

